\title{
Errata: Pulsed diode laser-based singlet oxygen monitor for photodynamic therapy: in vivo studies of tumor-laden rats
}

\author{
Seonkyung Lee \\ Danthu H. Vu \\ Michael F. Hinds \\ Steven J. Davis \\ Physical Sciences Inc. \\ 20 New England Business Center \\ Andover, Massachusetts 01810-1077 \\ E-mail: lee@psicorp.com
}

\section{Alvin Liang}

Tayyaba Hasan

Massachusetts General Hospital

Wellman Laboratories of Photomedicine

40 Blossom Street

Boston, Massachusetts 02114-2605

[DOI: $10.1117 / 1.3085950]$

Due to a publisher oversight, some author corrections to this article [J. Biomed. Opt. 13, 064035 (2008)] were not incorporated in the text prior to its publication. All online versions of the article were corrected on 29 December 2008. A listing of the corrections follows here:

1. On page 064035-3 line \#8 from the bottom left, the letter "p" before the word "diode" was deleted.

2. On page 064035-5, line \#7 from the top left, a hyphen was added between $\mathrm{Cl}$ and e6, and a hyphen was deleted between 0.5 and $\mathrm{mg}$.

3. On page 064035-7, line \#13 from the top left, the word "of" was deleted before "[PS]". 